\title{
Tailoring the Separation Behavior of Hybrid Organosilica Membranes by Adjusting the Structure of the Organic Bridging Group
}

\author{
H.L. Castricum1 \\ G.G. Paradis \\ M.C. Mittelmeijer-Hazeleger \\ R. Kreiter \\ J.F. Vente \\ J.E. ten Elshof ${ }^{2}$ \\ 1MESA+ \\ 2Uversity of Twente
}

Published in Advanced Functional Materials, Volume 21, 2011,

pages 2319-2329 


\title{
Tailoring the Separation Behavior of Hybrid Organosilica Membranes by Adjusting the Structure of the Organic Bridging Group
}

\author{
Hessel L. Castricum,* Goulven G. Paradis, Marjo C. Mittelmeijer-Hazeleger, \\ Robert Kreiter, Jaap F. Vente, and Johan E. ten Elshof
}

Hybrid organically linked silica is a highly promising class of materials for the application in energy-efficient molecular separation membranes. Its high stability allows operation under aggressive working conditions. Herein is reported the tailoring of the separation performance of these hybrid silica membranes by adjusting the size, flexibility, shape, and electronic structure of the organic bridging group. A single generic procedure is applied to synthesize nanoporous membranes from bridged silsesquioxane precursors with different reactivities. Membranes with short alkylene $\left(\mathrm{CH}_{2}\right.$ and $\left.\mathrm{C}_{2} \mathrm{H}_{4}\right)$ bridging groups show high $\mathrm{H}_{2} / \mathrm{N}_{2}$ permeance ratios, related to differences in molecular size. The highest $\mathrm{CO}_{2} / \mathrm{H}_{2}$ permeance ratios, related to the affinity of adsorption in the material, are obtained for longer $\left(\mathrm{C}_{8} \mathrm{H}_{16}\right)$ alkylene and aryl bridges. Materials with long flexible alkylene bridges have a hydrophobic surface and show strongly temperature-dependent molecular transport as well as a high $n$-butanol flux in a pervaporation process, which is indicative of organic polymerlike properties. The versatility of the bridging group offers an extensive toolbox to tune the nanostructure and the affinity of hybrid silica membranes and by doing so to optimize the performance towards specific separation challenges. This provides excellent prospects for industrial applications such as carbon capture and biofuel production.

\section{Introduction}

The most extensively used molecular separation technology, distillation, is responsible for an annual energy consumption equivalent to several hundred million barrels of oil. An estimated $50 \%$ energy reduction can be achieved when these processes are replaced by separation with membranes, which has

Dr. H. L. Castricum, Dr. J. E. ten Elshof

MESA+ Institute for Nanotechnology

University of Twente

P.O. Box 217, 7500 AE Enschede, The Netherlands

E-mail: h.l.castricum@uva.nl

Dr. H. L. Castricum, Dr. M. C. Mittelmeijer-Hazeleger

Van 't Hoff Institute for Molecular Sciences

University of Amsterdam

Science Park 904, 1098 XH Amsterdam, The Netherlands

Dr. H. L. Castricum, G. G. Paradis, Dr. R. Kreiter, Dr. J. F. Vente

Energy research Centre of the Netherlands

P.O. Box 1, 1755 ZG Petten, The Netherlands

DOI: 10.1002/adfm.201002361 a much higher thermodynamic efficiency. An example of such a process is pervaporation. This provides an efficient alternative to traditional thermal separation processes of liquids as it consists of the selective evaporation of only one of the components through a porous membrane. ${ }^{[1,2]}$ Gas separation is another energy-efficient application of membranes, which can be applied to relevant gas mixtures such as $\mathrm{H}_{2} / \mathrm{syn}$ gas and $\mathrm{CO}_{2} / \mathrm{CH}_{4} \cdot{ }^{[3,4]}$

Molecular separation membranes serve as barriers that favor transport of one component of a (gaseous or liquid) mixture. Nanoporous membranes can separate different small molecules through either molecular sieving or on the basis of affinity. If the mean pore size is close to the size of the smallest molecule, molecular sieving allows the separation of this molecule from larger ones. Separating larger molecules from smaller ones usually involves a specific interaction affinity of the molecule with the matrix. Several materials have been developed for use as a membrane, including organic polymers, ${ }^{[5,6]}$ zeolites, ${ }^{[7-11]}$ metal oxides, ${ }^{[12-14]}$ and silica. ${ }^{[10,15-22]}$ Polymers are highly versatile materials but they lack mechanical stability at temperatures above their glass transition temperature, and those that can be applied for pervaporation and gas separation generally have limited stability in organic solvents. They also suffer from plasticization effects, which reduce their selectivity at higher partial pressures or concentrations. Zeolites are difficult to grow in defect-free thin films, and stability issues have been reported as well..$^{7-9]}$ Microporous (pore size $<2 \mathrm{~nm}$ ) amorphous silica and metal oxide membranes consist of a multilayer composite structure coated on top of a mesoporous support system. ${ }^{[14,23]}$ These membranes are prepared by a sol-gel procedure that allows coating of a $<<1 \mu \mathrm{m}$-thin layer with high permeability and good selectivity. ${ }^{[10,15,16,18,19,24-26]}$ For molecular sieving of small molecules, pore sizes $<1 \mathrm{~nm}$ are applied. While metal oxides and inorganic silica have excellent thermal and mechanical stability, they generally lack stability for application in water-containing mixtures. ${ }^{[27,28]}$ In the presence of water, the lifetime of amorphous silica is limited to a few days at moderate temperatures 
$\left(<100{ }^{\circ} \mathrm{C}\right) .{ }^{[29]}$ The hydrothermal stability can be improved by using methylated silica ${ }^{[29-31]}$ to lifetimes in the order of weeks at $115^{\circ} \mathrm{C}$. The covalently built-in terminating methyl groups shield the Si-O-Si groups from hydrolysis, but also result in reduced separation factors because of the inherent bimodal pore size distribution. ${ }^{[32]}$ Other strategies that have been applied to improve the hydrothermal stability of silica include doping with metal oxides, ${ }^{[26,33]}$ and carbonization of noncovalently bonded templates. ${ }^{[34]}$

We recently developed an organosilica-based hybrid membrane composed of both organic and inorganic covalent links. The research focused on 1,2-bis(triethoxysilyl)ethane (BTESE), $(\mathrm{RO})_{3} \mathrm{Si}-\mathrm{C}_{2} \mathrm{H}_{4}-\mathrm{Si}(\mathrm{OR})_{3}$, a silsesquioxane with an ethylene bridging group between two $\mathrm{Si}$ moieties. Such bridged or organically linked silsesquioxanes, originally explored by Loy and Shea, ${ }^{[35,36]}$ inherently lead to strongly connected sol-gel networks because of their high number of reactive groups (up to six). Microporous membranes were prepared from mixtures of BTESE and methyltriethoxysilane, ${ }^{[37,38]}$ and from BTESE as a single precursor. ${ }^{[39]}$ These hybrid organosilica membranes were stable for at least 2 years in a pervaporation process, separating water from $n$-butanol at $150{ }^{\circ} \mathrm{C}$. In our assessment, most pervaporation processes of industrial interest can be carried out at or below this temperature. The materials combine a hydrothermal stability that is higher than that of any other existing microporous membrane with high solvolytical, mechanical, and thermal stabilities. Acid stability down to $\mathrm{pH}=2$ was demonstrated in both an inorganic (nitric) acid ${ }^{[39]}$ and an organic (acetic) acid. ${ }^{[40]}$ This exceptional stability is likely related to the connectivity in the network structure of the material, which limits on-stream formation and the growth of defects, as well as to enhanced toughness, which renders this class of materials highly resistant to crack formation. ${ }^{[41,42]}$

While the unprecedented stability of this material concept provides excellent prospects in industrial-scale separations, the technology will only become a success if several relevant mixtures can be separated. Tailoring of the separation performance, i.e., permeance and selectivity, is therefore a prerequisite for these hybrid membranes to become economically viable. A key advantage of hybrid organosilica materials is that they combine the best of two worlds, i.e., the network stability of inorganic silica, and the versatility of organic polymers. The possible number of variations in the organic (bridging) group is comparable to that of polymers. We recently reported that the nanostructure of hybrid membranes is likely related to the size of the organic bridging group. ${ }^{[40]}$ It was shown that a precursor having a single carbon bridging group is more selective for dewatering short alcohols than a precursor with a two-carbon (ethylene) bridge. Membranes based on BTESE were also tested for gas separation applications, ${ }^{[43-45]}$ showing that it is possible to prepare hydrogen-selective membranes.

In this study, we report how the applicability of molecular separation membranes can be tailored by adjusting the size, flexibility, and shape of the organic bridging group. The focus is on the synthesis of microporous (pore diameter $<2 \mathrm{~nm}$ ) materials, the size generally required for molecular separation. To assess the relation between the bridging group and the pore structure, no templates were used. The main goal of the study was to determine the relationship between the type of bridging

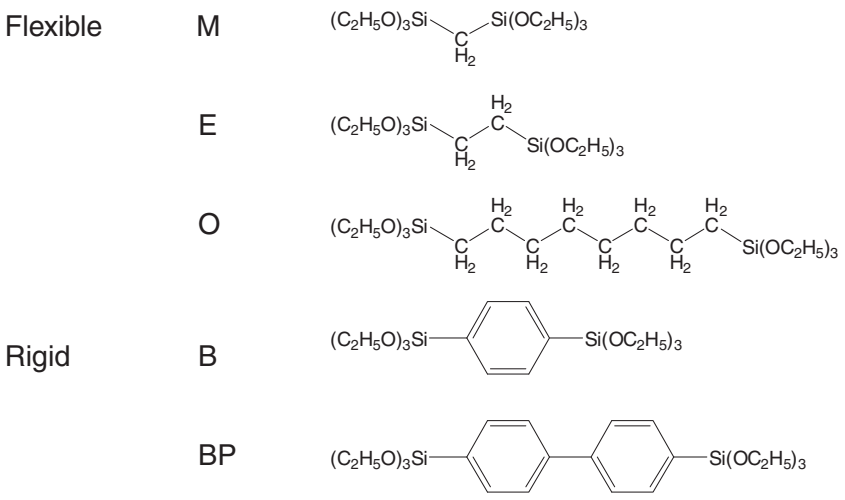

Scheme 1. Overview of the structural formulae of the bridged silsesquioxane precursors used in the synthesis of hybrid silica materials and the abbreviations used throughout the text.

group and the material's properties, rather than to optimize the permeance and selectivity of the membrane. We selected both linear alkylene bridges comprising $\mathrm{CH}_{2}, \mathrm{C}_{2} \mathrm{H}_{4}$, and $\mathrm{C}_{8} \mathrm{H}_{16}$, and the aromatic bridging groups benzene and biphenyl (Scheme 1). The latter two serve as rigid counterparts of the flexible alkylene-bridged silsesquioxanes. We anticipated that the pore size would be increased by applying longer bridging groups, and that this would be more apparent for rigid groups than for flexible ones. As the biphenyl bridge has approximately the same length as the octane bridge in a fully staggered conformation, the former should have larger pores than the latter. Similarly, the flexibility of the bridges should have an influence on the concentration and diffusivity of the species inside the membrane.

How a colloidal sol develops upon polymerization of bridged silsesquioxane precursors in condensation reactions is described first. The size of the colloids was tuned by adapting the concentration of the precursor, and was monitored with dynamic light scattering (DLS) and small-angle X-ray scattering (SAXS). Supported membranes were prepared from sols with a mean colloid size of $\approx 6 \mathrm{~nm}$. Application of similar colloid size distributions allowed optimal comparison of the structural and functional differences related to the organic bridging groups. The structure of unsupported materials was investigated with sorption techniques using various molecular probes, and the microporous character of supported membranes was assessed with permporometry. Finally, membrane performance was tested for relevant processes. Gas permeation and pervaporation experiments were carried out, and membrane applicability was determined from the permeance ratios. Our results show that the performance of hybrid silica ( $\mathrm{HybSi}$ ) membranes can be tailored towards specific separations by adjusting the size, flexibility, shape, and electronic structure of the organic bridging group.

\section{Results}

\subsection{Reactivity and Sol Structure}

Microporous membranes can be prepared by acid-catalyzed hydrolysis and condensation of silica precursors. A clear 
homogeneous sol containing colloids with a linearly branched network structure is required for the processing of microporous thin layers. ${ }^{[46]}$ For bridged silsesquioxanes, with $\mathrm{R}^{\prime}$ and $\mathrm{R}^{\prime \prime}$ representing the organic (bridging) group together with the other part of the bis-silane molecule attached, the generalized reactions can be described as follows:

Hydrolysis

$$
\begin{aligned}
& \mathrm{R}^{\prime}(\mathrm{RO})_{3-\mathrm{n}}-\mathrm{Si}-(\mathrm{OH})_{\mathrm{n}}+\mathrm{H}_{2} \mathrm{O} \\
& \quad \stackrel{\mathrm{H}^{+}}{\rightarrow} \mathrm{R}^{\prime}(\mathrm{RO})_{2-\mathrm{n}}-\mathrm{Si}-(\mathrm{OH})_{\mathrm{n}+1}+\mathrm{ROH}
\end{aligned}
$$

Condensation

$$
\begin{aligned}
& \mathrm{R}^{\prime}(\mathrm{RO})_{2-\mathrm{n}}-\mathrm{Si}-(\mathrm{OH})_{\mathrm{n}+1}+(\mathrm{HO})_{\mathrm{m}+1}-\mathrm{Si}-(\mathrm{OR})_{2-\mathrm{m}} \mathrm{R}^{\prime \prime} \stackrel{H^{+}}{\rightarrow} \\
& \mathrm{R}^{\prime}(\mathrm{RO})_{2-\mathrm{n}}(\mathrm{OH})_{\mathrm{n}}-\mathrm{Si}-\mathrm{O}-\mathrm{Si}-(\mathrm{OR})_{2-\mathrm{m}}(\mathrm{OH})_{\mathrm{m}} \mathrm{R}^{\prime \prime}+\mathrm{H}_{2} \mathrm{O}
\end{aligned}
$$

with $n, m=0,1$, or 2 . The reactivity of the precursors is strongly dependent on the electron donating or withdrawing properties of the groups that bind to the $\mathrm{Si}$ atom. This causes the reactivity of bridged silsesquioxane molecules to be higher than of tetraethylorthosilicate, from which (inorganic) silica $\left(\mathrm{SiO}_{2}\right)$ is prepared. ${ }^{[47]}$ While detailed characterization with ${ }^{29} \mathrm{Si}$ NMR has limitations related to the complexity of the formed molecules, a fast measure of the degree of polymerization can be obtained by assessing the size of the colloidal particles with DLS. ${ }^{[4]}$ The size of the colloids provides a good indication of the applicability of a sol for thin-film coating. Deposition of colloids smaller than the mean pore size of a porous support does not lead to a welldefined layer but rather to extensive penetration of the colloids into the support, while very large colloids in sols close to the gel point result in thick layers that are highly prone to crack formation. ${ }^{[38]}$

For the selected silsesquioxane precursors, we investigated how colloidal sols could be synthesized that are suitable for the thin-film coating of molecular separation membranes. According to Equation (2), the condensation rate is second order in $\mathrm{Si}-\mathrm{OH}$. The rate thus depends on the square of the monomer concentration and on the probability that monomers with reactive groups form a bond upon collision. This probability is a function of the number and type of groups bound to a $\mathrm{Si}$ atom $(-\mathrm{OH},-\mathrm{OR},-\mathrm{OSi})$, and therefore changes during the development of colloidal particles. As a rapid and discontinuous increase of the viscosity towards a continuous network, a so-called gel, does not allow the coating of thin layers, we were interested in a region far from this gel point. We therefore focused on conditions that would not lead to gelation of the mixture during reaction or in the subsequent $\approx 1 \mathrm{~h}$ period of room-temperature processing towards thin layers. Colloid sizes were varied by applying different silsesquioxane precursor concentrations (Table 1), keeping all other reaction parameters constant, i.e., catalyst $\left(\mathrm{HNO}_{3}\right)$ concentration, hydrolysis ratio, reaction temperature, and synthesis time. Abridged designations are applied below for sols from bis(triethoxysilyl)methane (M1, M2...), 1,2-bis(triethoxysilyl) ethane (E1, E2...), etc.

\begin{tabular}{|c|c|c|c|c|c|}
\hline \multirow[b]{2}{*}{ Precursor } & \multicolumn{4}{|c|}{ [Si] $\left[\mathrm{mol} \mathrm{L}^{-1}\right]$ in experiment \# } & \multirow{2}{*}{$\begin{array}{l}s_{\mathrm{c}}=d_{\text {hyd }}{ }^{0.5} /[\mathrm{Si}] \\
{\left[\mathrm{nm}^{1 / 2} \mathrm{~L} \mathrm{~mol}^{-1}\right]}\end{array}$} \\
\hline & 1 & 2 & 3 & 4 & \\
\hline M & 0.6 & 0.9 & 1.2 & 1.8 & 2.2 \\
\hline E & 0.6 & 0.9 & 1.2 & 1.8 & 2.1 \\
\hline 0 & 0.2 & 0.3 & 0.4 & 0.6 & 8.5 \\
\hline B & 0.25 & 0.375 & 0.5 & 0.75 & 7.4 \\
\hline BP & 0.133 & 0.2 & 0.267 & 0.4 & 14 \\
\hline
\end{tabular}

Table 1. Si molar concentrations (silsesquioxane precursor concentrations are half of these values) applied in the synthesis of colloidal sols, and the slope $\mathrm{s}_{\mathrm{c}}$ of the dependency of $d_{\text {hyd }}{ }^{1 / 2}$ on [Si] after $3 \mathrm{~h}$ at $333 \mathrm{~K}$.

Colloid size distributions were acquired with DLS, and are displayed in Figure $\mathbf{1}$ for the ' $E$ '-series. Larger colloid sizes were obtained with increasing monomer concentration. The broad distributions, indicating polydispersity, became broader with increasing size for sols from all precursors. At low concentration a linear dependency was found of the root of the mean hydrodynamic diameter $d_{\text {hyd }}$ on the precursor concentration (Figure 2). This empirical correlation is in agreement with the second-order condensation rate with respect to $\mathrm{Si}-\mathrm{OH}$. At higher concentrations, however, much larger sizes were observed than expected based on this correlation. This sharp size increase with concentration found at a colloid size $>15 \mathrm{~nm}$ can be explained by the dominance of colloid-colloid aggregation in the growth process above this threshold, rather than the reaction of monomer species with colloids at sizes below the threshold. Interaction between two large colloids resulting in aggregation is more likely for further-developed sols, obtained at higher concentrations. This is in agreement with the broad colloid size distribution at the highest concentration (cf. E4 in Figure 1). Colloid-colloid aggregation may eventually lead to gelation, i.e., the formation of a continuous network structure. A measure for the reactivity of the precursor is the slope $s_{\mathrm{c}}$ of the linear relation between $d_{\mathrm{hyd}}{ }^{1 / 2}$ and the Si concentration (Table 1). The fact that the correlation is similar for all bridged silsesquioxanes implies that the sizes of all colloidal sols can be tuned in a similar manner.

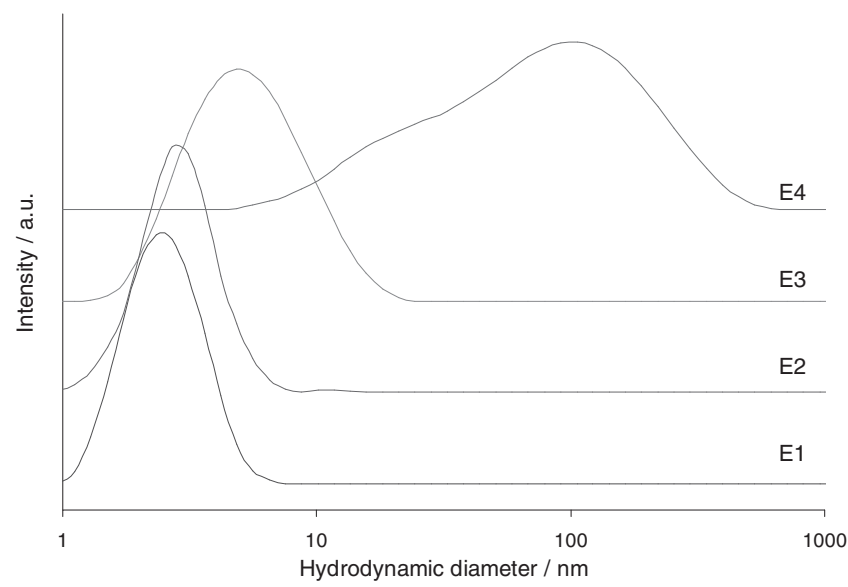

Figure 1. Size distributions of 1,2-bis(triethoxysilyl)ethane colloidal sols determined with dynamic light scattering. For the designations of the samples see 1 . 


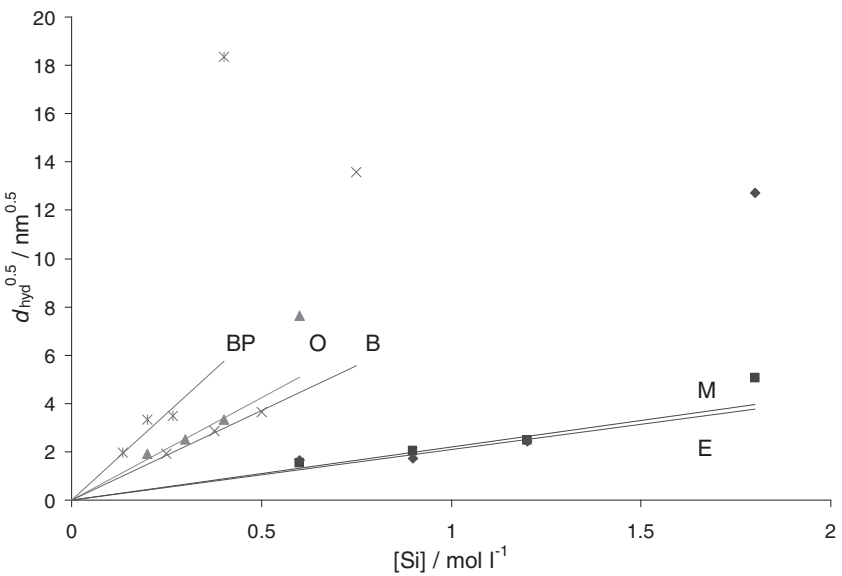

Figure 2. Square root of the mean hydrodynamic diameter $d_{\text {hyd }}$ of organosilica colloidal sols, determined with DLS, versus the Si concentration (M: squares; E: diamonds). The size of the data points is indicative of the experimental error. A linear relation has been fitted at the lower concentrations.

In view of the colloid size dependency on concentration, a series of sols was synthesized from the recipes ' 3 ' (Table 1) with a mean size of around $6 \mathrm{~nm}$, i.e., in the regime in which colloid growth is dominated by the reaction with monomer species. In order to obtain the same mean size, the synthesis time at $333 \mathrm{~K}$ was reduced to $50 \mathrm{~min}$ for the recipes based on octane- and benzene-bridged silsesquioxanes, and to $30 \mathrm{~min}$ for the biphenyl-bridged silsesquioxane. The hydrodynamic diameter of the colloids was monitored by DLS. The size was larger than the 3-4 nm mesopore diameter of the $\gamma-\mathrm{Al}_{2} \mathrm{O}_{3}$ membrane support, so that infiltration of the sol into the substrate does not occur. At the same time, this colloid size was sufficiently small to prepare thin layers. ${ }^{[38]}$ The size distributions were very similar for all of the precursors (Figure 3). The colloidal sols were diluted with an equal amount of ethanol directly after synthesis. Thereafter, the sols showed no measurable change in colloid size within a time frame of several hours.

Small-angle X-ray scattering patterns (Figure 4a) were collected for these sols. The patterns exhibit a power-law relation at

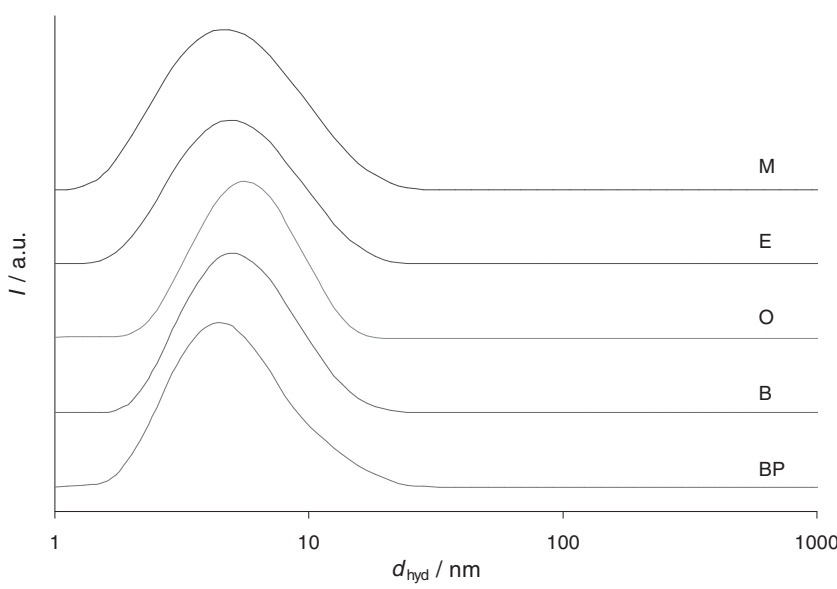

Figure 3. Colloid size distributions of organosilica sols with a mean diameter of $\approx 6 \mathrm{~nm}$. a)

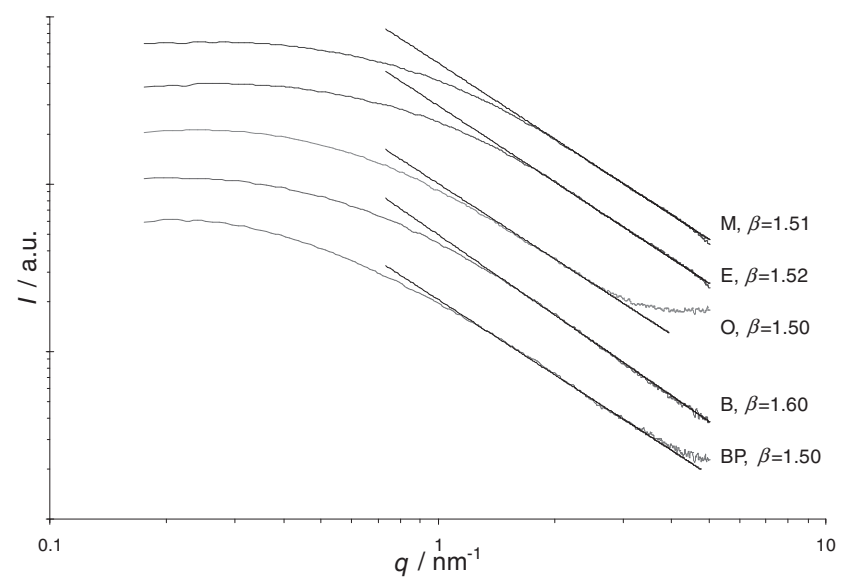

b)

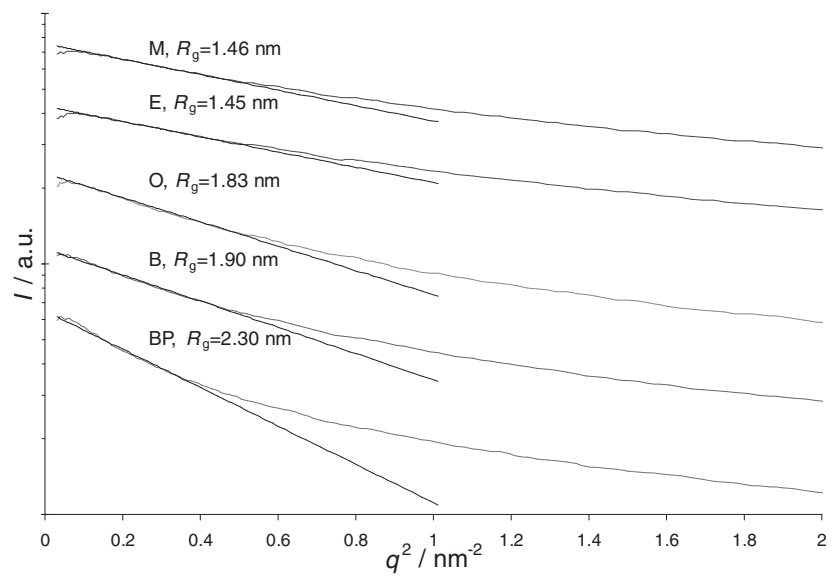

Figure 4. a) SAXS patterns of organosilica colloidal sols, and powerlaw relations $I \sim \mathrm{e}^{-\beta}$ fitted to the high- $q$ part of these patterns. b) Low- $q$ part of SAXS patterns of organosilica sols, fitted with the relation I $\exp \left(-R_{\mathrm{g}}{ }^{2} q^{2} / 3\right)$.

$q>1 \mathrm{~nm}^{-1}$. Fitting the relationship $I \sim q^{-\beta}$ to the scattering pattern gives values of $\beta$ between 1.5 and 1.6 (Table 2). For a small colloidal particle, the value of $\beta$ gives an indication of the degree of branching, expressing the internal structure of the particle. For truly fractal systems, in which this relationship extends over several orders of magnitude, it expresses the so-called fractal dimension. However, this regime can obviously only be observed in a limited $q$-range for these nanometer-sized colloids. For the system under consideration here, the obtained $\beta$ values imply that the colloids can be described as slightly branched structures. The power-law relation is observed in a $q$-range that varies between $1.1-5 \mathrm{~nm}^{-1}$ and $1.7-5 \mathrm{~nm}^{-1}$. These ranges correspond to approximate length scales $d \sim 2 \pi / q$ between $\approx 1.2$ and $4-6 \mathrm{~nm}$. No information was obtained above $q=5 \mathrm{~nm}^{-1}$, i.e., at length scales smaller than about $1.2 \mathrm{~nm}$. The patterns show no peaks or sharp cut-offs, which suggests that no periodicity is occurring and that the distributions are polydisperse. For the $\mathrm{O}$ and $\mathrm{BP}$ sols, a relatively 
Table 2. Analytical data for bridged silsesquioxane colloidal sols: exponent $\beta$ of the power-law relation $I \sim q^{-\beta}$, indicating the degree of branching of the structure; smallest $q_{\min }$ p, and corresponding largest diameter $d_{\max p l}$ of the power-law regime; radius of gyration $R_{\mathrm{g}}$ from Guinier regime and corresponding colloid diameter $d_{\text {Guinier }}$ assuming a spherical particle; mean hydrodynamic diameter $d_{\text {hyd }}$ determined with DLS.

\begin{tabular}{|c|c|c|c|c|c|c|}
\hline Precursor & $\beta$ & $q_{\text {min_pl }}\left[\mathrm{nm}^{-1}\right]$ & $d_{\text {max_pl }}[\mathrm{nm}]$ & $R_{\mathrm{g}}[\mathrm{nm}]$ & $d_{\text {Guinier }}[\mathrm{nm}]$ & $d_{\text {hyd }}[\mathrm{nm}]$ \\
\hline M & 1.51 & 1.7 & 3.7 & 1.46 & 3.8 & 5.9 \\
\hline E & 1.52 & 1.6 & 3.9 & 1.45 & 3.7 & 6.0 \\
\hline O & 1.50 & 1.3 & 4.8 & 1.83 & 4.7 & 6.3 \\
\hline B & 1.60 & 1.3 & 4.8 & 1.90 & 4.9 & 6.1 \\
\hline BP & 1.50 & 1.1 & 5.7 & 2.30 & 5.9 & 6.4 \\
\hline
\end{tabular}

high scattering intensity was observed in the upper $q$ range. This is probably related to the comparatively large size of the precursor molecules, which gives a persistence length of electron density variations of the order of $1 \mathrm{~nm}$, close to the upper limit of the acquired scattering pattern. The $\beta$ values between 1.5 and 1.6 indicate that the colloids have an open polymeric network structure. This is crucial for the synthesis of microporous materials, as the values are sufficiently small to allow the colloidal particles to interpenetrate upon solvent evaporation and to form a continuous film without mesopores. ${ }^{[46,48]}$ Consequently, ample new $\mathrm{Si}-\mathrm{O}-\mathrm{Si}$ bonds between the particles are formed during the coating of thin layers, and no hard-sphere packing occurs in this process. The final microstructure is therefore not determined by colloid size, but rather by intrachain porosity, i.e., the space between the polymeric chains of the colloidal particles. Hard-sphere packing would only occur in the case of highly branched colloids with a $\beta$ value close to 3 , leading to mesoporous structures. ${ }^{[46]}$ The size of the colloidal particles can be described in terms of the gyration radius $R_{\mathrm{g}}$, which was determined from the Guinier regime, in the lower $q$ range of the patterns. Fits to the equation $I \sim \exp \left(-R_{\mathrm{g}}{ }^{2} q^{2} / 3\right)^{[49]}$ are shown in Figure 4b. Assuming a spherical shape, the gyration radius $R_{\mathrm{g}}$ is related to the diameter of the particle $d_{\text {Guinier }}$ via $d_{\text {Guinier }}=2 R_{\mathrm{g}}(5 / 3)^{1 / 2}$ (Table 2 ). These values correspond well to $d_{\text {max_pl }}$, the dimension related to the lower limit of the power-law regime (at smallest $q_{\text {min_pl }}$ ). In comparison, the hydrodynamic diameter determined with DLS also includes the solvation sphere of the colloidal particles. From the difference between this value and the characteristic diameters obtained with SAXS, the thickness of the solvation sphere can be estimated to be around $1 \mathrm{~nm}$. Interestingly, the difference between the values becomes smaller as the C/Si ratio increases, suggesting a smaller contribution of the solvation sphere to the diameter.

\subsection{Organosilica Nanostructure}

Unsupported solid films were prepared from the colloidal sols with $\approx 6 \mathrm{~nm}$ colloid size by submitting them to a rapid drying procedure. The materials were subsequently thermally consolidated by a heat treatment under nitrogen to remove any volatile components, resulting in a high degree of network condensation. The stability of the organic bridging groups towards thermal consolidation was confirmed with Fourier-transform IR (FTIR) spectroscopy by observation of the symmetric and asymmetric stretching bands of the $\mathrm{C}-\mathrm{H}$ bonds in the high-frequency range (Figure 5). The characteristic vibrations of $\mathrm{CH}_{2}$ in the alkylene-bridged materials were observed between 2800 and $3000 \mathrm{~cm}^{-1}$, and those of $\mathrm{CH}$ in the aromatic groups of the benzene- and biphenyl-bridged organosilica materials between 2950 and $3100 \mathrm{~cm}^{-1}$. No indications were found that decomposition of the organosilica groups had occurred in the materials. Interestingly, the intensities of the characteristic vibrations of water, i.e., the $3000-3700 \mathrm{~cm}^{-1}$ band corresponding to $-\mathrm{OH}$ stretching modes and the $1637 \mathrm{~cm}^{-1}$ peak corresponding to the $\mathrm{H}-\mathrm{O}-\mathrm{H}$ bending mode, were significantly lower for the octane-bridged material than for the other organosilicas, indicating a lower amount of adsorbed water for this material. As the storage conditions were identical for all materials, the difference in intensity can be explained by a more hydrophobic character of the octane-bridged material. This is consistent with a decreased selectivity to water transport through this material as observed in a pervaporation experiment discussed below (Section 2.3).

The skeletal density was probed with He pycnometry. Long equilibrium times of 1-2 min were needed to accurately determine the density, which is an indication of very small pore sizes. As compared to $\mathrm{SiO}_{2}$, which has a density of $2.2 \mathrm{~g} \mathrm{~cm}^{-3}$, lower densities were observed for the organosilica materials. The $\mathrm{M}$ and $\mathrm{E}$ materials and the B and BP materials had similar

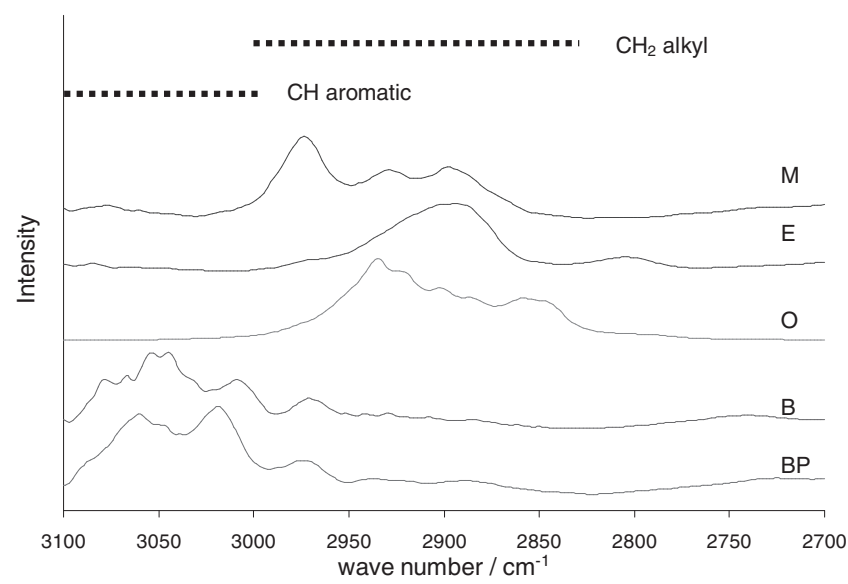

Figure 5. FTIR spectra of organosilica materials, displaying the symmetric and asymmetric stretching bands of the $\mathrm{C}-\mathrm{H}$ bonds of the organic bridges. The regions of the characteristic vibrations are indicated for $\mathrm{CH}$ in aromatic groups and $\mathrm{CH}_{2}$ in alkylene groups. 
Table 3. Analytical data for solid materials prepared from bridged silsesquioxanes: skeletal density (He pycnometry, error in the last digit in parentheses), pore volume $v_{\mathrm{p}}\left(\mathrm{N}_{2}\right.$ adsorption), surface areas $A$ determined from Dubinin fits ${ }^{[0,57,58]}$ of $\mathrm{N}_{2}, \mathrm{CO}_{2}, \mathrm{C}_{2} \mathrm{H}_{4}$, and $\mathrm{C}_{2} \mathrm{H}_{2}$ adsorption isotherms, and $D$ constant for the fit of the $\mathrm{CO}_{2}$ isotherm.

\begin{tabular}{|c|c|c|c|c|c|c|c|}
\hline Material & $\rho_{\text {skeletal }}$ & $v_{\text {pore }}\left[\mathrm{mL} \mathrm{g}^{-1}\right]$ & $A_{N_{2}}\left[\mathrm{~m}^{2} \mathrm{~g}^{-1}\right]$ & $A_{\mathrm{CO}_{2}}\left[\mathrm{~m}^{2} \mathrm{~g}^{-1}\right]$ & $A_{\mathrm{C}_{2} \mathrm{H}_{4}}\left[\mathrm{~m}^{2} \mathrm{~g}^{-1}\right]$ & $A_{\mathrm{C}_{2} \mathrm{H}_{2}}\left[\mathrm{~m}^{2} \mathrm{~g}^{-1}\right]$ & $D\left(\mathrm{CO}_{2}\right)$ \\
\hline M & $1.69(2)$ & 0.01 & 4 & 386 & 310 & 451 & 0.165 \\
\hline E & $1.66(4)$ & 0.06 & 120 & 367 & 537 & 558 & 0.163 \\
\hline $\mathrm{O}$ & $1.28(6)$ & 0 & 0 & 144 & 83 & 132 & 0.261 \\
\hline B & 1.41 (2) & 0 & 0 & 481 & 525 & 642 & 0.163 \\
\hline BP & $1.43(2)$ & 0.04 & 77 & 290 & 453 & - & 0.160 \\
\hline
\end{tabular}

skeletal densities (Table 3). The lowest value was found for the octane-bridged material. The differences can be related to the volume taken by the organic bridge. The low value found for the O material as compared to B or BP is in agreement with the general observation that aliphatic groups take up a larger volume per carbon atom than aromatic groups.

Pore structures were investigated with gas adsorption. In view of the mostly microporous character of the materials, several molecular probes were used to obtain information on the pore structure. With $\mathrm{N}_{2}$, nonzero surface areas and pore volumes were only found for M, E, and BP (Table 3), although the values for $M$ were very small. The $\mathrm{N}_{2}$ isotherms showed no hysteresis and were all of type I, indicating full microporosity. For the other molecular probes, nonzero surface areas were observed for all materials. As $\mathrm{N}_{2}$ is not much larger than the other molecules, the small surface areas are probably related to the low temperature applied for $\mathrm{N}_{2}$ adsorption $(77 \mathrm{~K})$, while adsorption of all other molecular probes was measured at $273 \mathrm{~K}$. This likely resulted in more kinetic hindrance of $\mathrm{N}_{2}$ transport into the pores. For adsorption of $\mathrm{CO}_{2}, \mathrm{C}_{2} \mathrm{H}_{4}$, and $\mathrm{C}_{2} \mathrm{H}_{2}$, the surface area is strongly dependent on the type of molecule. The adsorption of $\mathrm{C}_{2} \mathrm{H}_{4}$, having the largest kinetic diameter, was lower on $\mathrm{M}$ and, especially, on $\mathrm{O}$ than adsorption of $\mathrm{CO}_{2}$ and $\mathrm{C}_{2} \mathrm{H}_{2}$. This indicates that $\mathrm{M}$ and $\mathrm{O}$ materials have very small micropores. Interestingly, more $\mathrm{C}_{2} \mathrm{H}_{4}$ than $\mathrm{CO}_{2}$ was absorbed on the E, B, and BP materials. This indicates that the pores are sufficiently large to allow unhindered adsorption of ethylene, and also suggests a specific interaction between $\mathrm{C}_{2} \mathrm{H}_{4}$ and the matrices. For the E material, the high amount of adsorbed $\mathrm{C}_{2} \mathrm{H}_{4}$ is likely related to the similarly sized ethylene bridge, causing the $\mathrm{C}_{2} \mathrm{H}_{4}$ molecule to be better contained than $\mathrm{CO}_{2}$. For the $\mathrm{B}$ and BP materials, $\pi-\pi$ interaction between the $\mathrm{C}=\mathrm{C}$ bridge and the aryl groups is the likely cause of enhanced $\mathrm{C}_{2} \mathrm{H}_{4}$ adsorption. This is also in agreement with the observation that the relative difference is larger for the BP material, which contains more aryl groups. The measured surface areas suggest the following order of the pore sizes: $\mathrm{O}<\mathrm{M}<\mathrm{E}$ for the alkylene-bridged materials and $\mathrm{B}<\mathrm{BP}$ for the materials with aromatic bridges. The $D$-constant from the Dubinin fit (Equation (4)) gives the dependency of the actual adsorbed amount on the relative pressure. All values were of the same order for these materials, except in the case of the $O$ material, for which values 1.4-1.6 times larger were observed. A larger value is generally related to a lower adsorption potential. ${ }^{[50]}$ The low surface areas that were measured in the $\mathrm{O}$ material with all vapors is thus not necessarily related to a small pore size. The hindered gas adsorption into the pores of this material, however, indicates that that the conformation of the octane bridge is random rather than fully staggered. A staggered conformation would leave ample space available between the $\mathrm{Si}-\mathrm{O}-\mathrm{Si}$ groups for molecular transport.

\subsection{Membrane Structure and Gas Permeation Performance}

From the sols with $6 \mathrm{~nm}$ colloid diameter, membranes were synthesized following a well-established coating procedure, ${ }^{[51,52]}$ followed by thermal consolidation. By starting with the same colloid size distribution for all materials, we ensured that we could optimally compare the functionality of the organic groups. Thicknesses of selective layers were determined with scanning electron microscopy (SEM) and are summarized in Table 4. A typical micrograph of the cross-section of the top part of a membrane is shown in Figure 6. The elemental composition of the top layer ( $\mathrm{Si}$ ) and the supporting layers (Al) could well be distinguished with energy dispersive X-ray (EDX) spectroscopy. The thicknesses of the membranes were all in the same range, which was also anticipated from the similarity of the sol properties and the coating conditions. The microporous character of the selective layers was assessed with permporometry. ${ }^{[53,54]}$ The pore-size distributions differed clearly from that of the mesoporous $\gamma-\mathrm{Al}_{2} \mathrm{O}_{3}$ membrane support (see Supporting Information), indicating that the top layers of all membranes were essentially free of defects.

To acquire information on the applicability of membranes for separating small molecules $(<<1 \mathrm{~nm})$, single gas permeances of $\mathrm{H}_{2}, \mathrm{He}, \mathrm{CO}_{2}, \mathrm{~N}_{2}$, and $\mathrm{CH}_{4}$ were measured at different pressures and temperatures. Control measurements before and after the whole procedure were identical, showing that no structural changes occurred in any of the membrane materials during the measurements. A linear increase of the permeance with the

Table 4. Thickness of the membrane top layer of organosilica membranes, and $\mathrm{H}_{2}$ and $\mathrm{CO}_{2}$ permeances at a feed pressure of 3 bar.

\begin{tabular}{lccc}
\hline Membrane & $\begin{array}{c}\text { Thickness } \\
{[\mathrm{nm}]}\end{array}$ & $\begin{array}{c}\mathrm{H}_{2} \text { permeance, } 523 \mathrm{~K} \\
{\left[10^{-6} \mathrm{~mol} \mathrm{~m}^{-2} \mathrm{~Pa}^{-1} \mathrm{~s}^{-1}\right]}\end{array}$ & $\begin{array}{c}\mathrm{CO}_{2} \text { permeance, } 323 \mathrm{~K} \\
{\left[10^{-6} \mathrm{~mol} \mathrm{~m}^{-2} \mathrm{~Pa}^{-1} \mathrm{~s}^{-1}\right]}\end{array}$ \\
\hline $\mathrm{M}$ & 160 & 1.79 & 1.85 \\
$\mathrm{E}$ & 185 & 1.29 & 0.81 \\
$\mathrm{O}$ & 158 & 2.32 & 0.56 \\
$\mathrm{~B}$ & 230 & 1.52 & 1.82 \\
$\mathrm{BP}$ & 140 & 1.93 & 2.11 \\
\hline
\end{tabular}




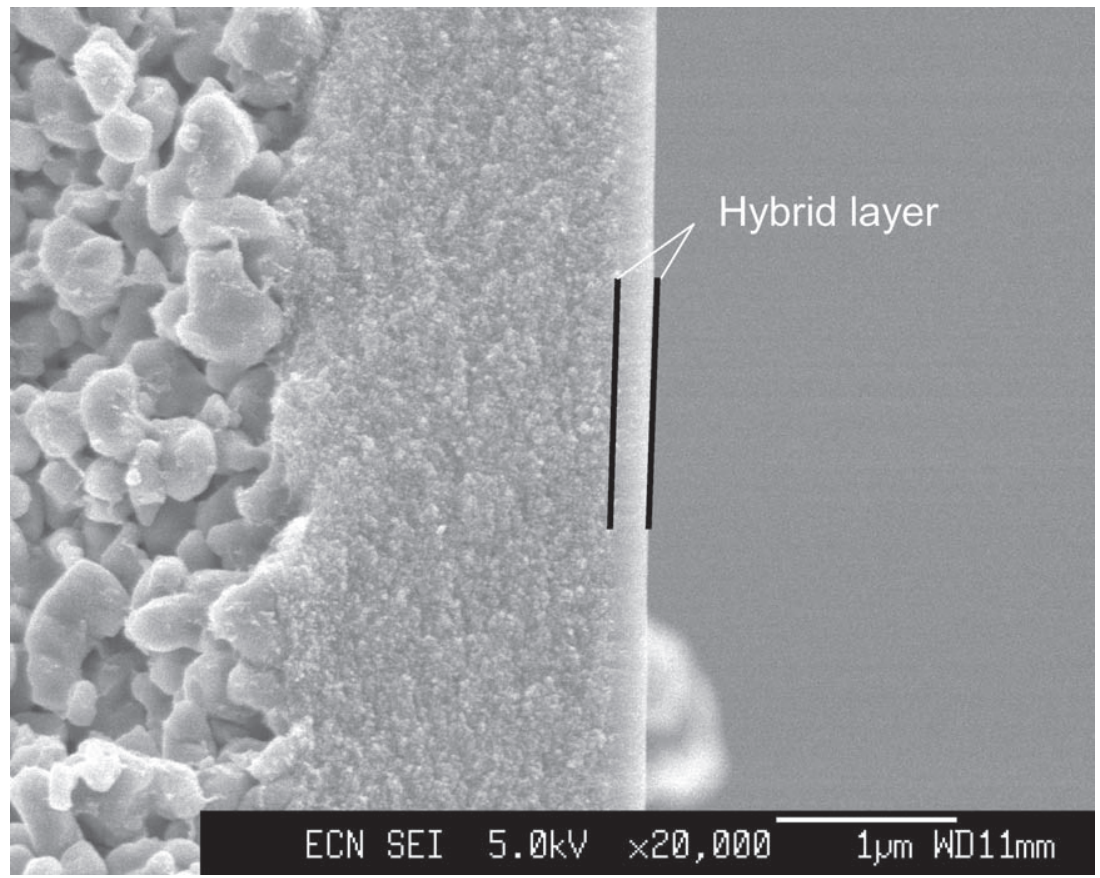

Figure 6. Cross-sectional SEM image of an $\mathrm{M}$ membrane, showing from left to right the macroporous $\alpha-\mathrm{Al}_{2} \mathrm{O}_{3}$ support layer, the mesoporous $\gamma-\mathrm{Al}_{2} \mathrm{O}_{3}$ interlayer and the microporous hybrid top-layer. The organosilica hybrid layer has a thickness of $160 \mathrm{~nm}$. the filling of material becomes nonHenry at increased pressures, meaning that there is no linear relation between with pressure and pore filling. Higher pressures thus result in a lower permeance (transport divided by pressure) through the membrane. The absence of pressure-dependent transport for the other gases indicates that adsorption effects have a lesser influence on the permeance.

Different temperature dependencies were observed for the gas permeances. For all membranes, the $\mathrm{H}_{2}$ and $\mathrm{He}$ permeances increased with increasing temperature, while those of $\mathrm{CO}_{2}$ decreased. For the $\mathrm{O}$ membrane, however, the $\mathrm{CO}_{2}$ permeance also increased with increasing temperatures. For $\mathrm{N}_{2}$ and $\mathrm{CH}_{4}$, the changes were of the same order as for $\mathrm{H}_{2}$ and $\mathrm{He}$, although a small decrease with increasing temperature was also observed for several materials. The $\mathrm{O}$ membrane showed the largest permeance increase at higher temperatures for all gases (including $\mathrm{CO}_{2}$ ). Apparent activation energies $E_{\text {app }}$ were calculated from the temperature-dependent permeances and are displayed in Figure 8. These values are related to the activation energy for diffusion $E_{\text {act }}^{\mathrm{D}}$ according to: ${ }^{[16]}$ average pressure (Poiseuille viscous flow) added to a pressureindependent diffusion term would be expected when macroscopic defects have a significant contribution to the overall gas transport. ${ }^{[55]}$ Since the gases expected to have a low sorption component $\left(\mathrm{He}\right.$ and $\mathrm{N}_{2}$ ) show very little pressure dependence (e.g., for the $\mathrm{M}$ membrane at $323 \mathrm{~K}$, shown in Figure 7), this confirms that all membranes were virtually free of macroscopic defects. A decreasing permeance with increasing feed pressure was observed for $\mathrm{CO}_{2}$ at $323 \mathrm{~K}$ for all membranes, except for the $\mathrm{O}$ membrane. This is indicative of a strong influence of adsorption effects. Transport depends on both pore diffusivity and surface diffusivity. The latter depends on the concentration of adsorbed species. For strongly adsorbing $\mathrm{CO}_{2}$ molecules,

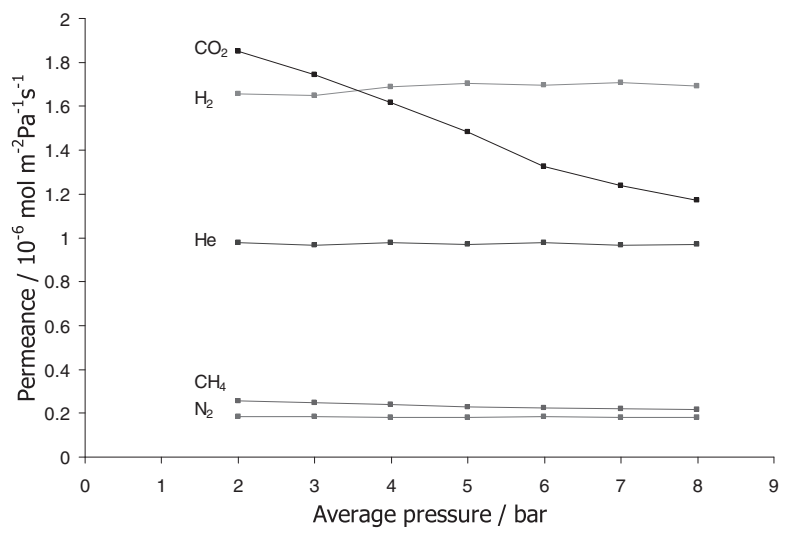

Figure 7. Dependence of gas permeances on the average pressure with a constant pressure drop of 2 bar through an organosilica $\mathrm{M}$ membrane at $323 \mathrm{~K}$.
$E_{\mathrm{app}}=E_{\mathrm{act}}^{\mathrm{D}}-Q$

with $Q$ being the isosteric heat of molecular adsorption. The temperature-dependent permeance of $\mathrm{CO}_{2}$ appears as generally negative apparent activation energies, which can again be explained by a stronger interaction of this gas with the hybrid organosilica materials. Strong interaction with $\mathrm{CO}_{2}$ was also observed for $\mathrm{SiO}_{2}$ membranes and can be associated with the presence of hydroxyl groups. ${ }^{[16]}$ A weaker interaction was found in methylated silica membranes. ${ }^{[31]}$ The generally very high permeance of $\mathrm{CO}_{2}$, especially at low temperatures (Table 4), is of interest, considering that surface diffusivity in molecular sieving membranes is generally lower than pore diffusivity. This can again be related to the high filling of the material with $\mathrm{CO}_{2}$. Possibly, $\mathrm{CO}_{2}$ solubility into the organic bridging chains of hybrid silica materials is an additional factor.

The transport results through the $\mathrm{O}$ membrane show much higher overall values for $E_{\text {app }}$ than those through the other materials. The strongly enhanced transport at higher $T$ has not been observed before in silica and other ceramic membranes and is reminiscent of molecular transport through polymeric materials. In polymers, increased diffusivity at higher temperatures is related to an increased mobility of the organic chains in the material. Considering that the $\mathrm{O}$ material contains long flexible organic bridges, the permeance through this material may similarly be related to temperature-dependent chain mobility. The large values for $E_{\text {app }}$ for the $\mathrm{O}$ membrane would result in near-zero transport at $273 \mathrm{~K}$, which is in agreement with the hindered adsorption observed at this temperature for several vapors (Section 2.2). Transport through the other membranes depends much less on the temperature, which can be ascribed to a greater rigidity of the matrix. 


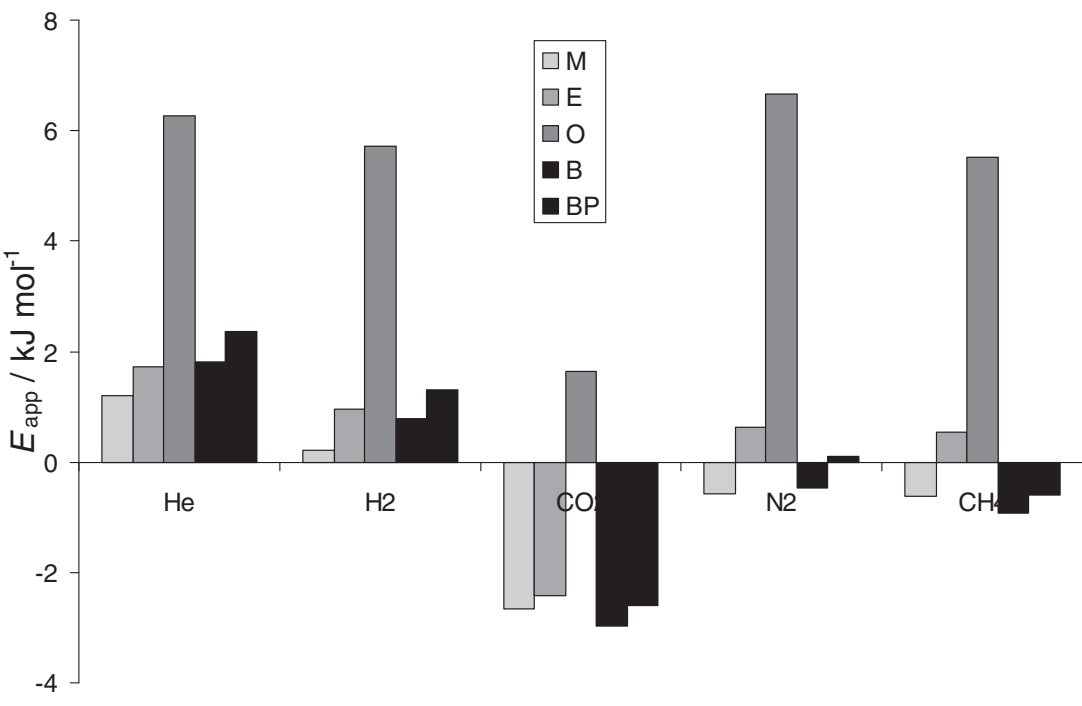

Figure 8. Apparent activation energies $E_{\text {app }}$ of the permeance of various gases through organosilica membranes, averaged for feed pressures of 3-9 bar.

By assessing the permeance ratios of the different gases, we confirmed that we had prepared a series of membranes with fully different properties. Relevant permeance ratios of $\mathrm{H}_{2} / \mathrm{N}_{2}$ $(523 \mathrm{~K}), \mathrm{CO}_{2} / \mathrm{CH}_{4}(323 \mathrm{~K})$ and $\mathrm{CO}_{2} / \mathrm{H}_{2}(323 \mathrm{~K})$ are listed in Table 5. The differences between the membranes are closely related to the size and shape of the bridging groups. The highest $\mathrm{H}_{2} / \mathrm{N}_{2}$ permeance ratios were found for the $\mathrm{M}$ and $\mathrm{E}$ membranes, which have the smallest organic bridge lengths. Considering that $\mathrm{H}_{2}$ has a smaller kinetic diameter than $\mathrm{N}_{2}$, these permeance ratios are indicative of size-based molecular sieving related to the nanostructure of the materials. The size difference between the $\mathrm{M}$ and $\mathrm{E}$ bridges is apparently too small to lead to a clear difference in gas permeance ratio in this membrane series. The $\mathrm{H}_{2} / \mathrm{N}_{2}$ permeance ratios were smaller for the $\mathrm{O}, \mathrm{B}$, and $\mathrm{BP}$ membranes, which have much larger organic bridges. For all membranes, the $\mathrm{H}_{2}$ permeances (Table 4) were high, and of the same order as for other sol-gelderived silica ${ }^{[16,31]}$ and hybrid silica ${ }^{[43-45]}$ membranes. Hybrid membranes therefore show potential to be further developed towards hydrogen-separation applications. The highest $\mathrm{H}_{2}$ permeance at high temperature $(523 \mathrm{~K})$ was observed for the $\mathrm{O}$ material (Table 4).

As $\mathrm{CO}_{2}$ has a larger kinetic diameter than $\mathrm{H}_{2}, \mathrm{CO}_{2} / \mathrm{H}_{2}$ permeance ratios $>1$ are not related to size, but rather to differences in the affinity for adsorption or in solubility. The strong interaction of $\mathrm{CO}_{2}$ with the surface of hybrid materials is, as mentioned above, the likely cause of faster transport of $\mathrm{CO}_{2}$ than of $\mathrm{H}_{2}$ at lower temperatures. Interestingly, $\mathrm{CO}_{2} / \mathrm{H}_{2}$ ratios $<<1$ were observed for silica and methylated silica membranes. ${ }^{[16,31]}$ The molecularsieving effect is likely too prominent in those materials to allow molecular transport based on differences in affinity. The $\mathrm{CO}_{2} / \mathrm{H}_{2}$ ratios at $323 \mathrm{~K}$ were highest for the $\mathrm{O}, \mathrm{B}$, and $\mathrm{BP}$ membranes, and substantially smaller for the $\mathrm{M}$ and $\mathrm{E}$ membranes. As $\mathrm{CO}_{2}$ has a smaller kinetic diameter than $\mathrm{CH}_{4}$, the high $\mathrm{CO}_{2} / \mathrm{CH}_{4}$ permeance ratios are expectedly related to a combination of size-based molecular sieving and a stronger interaction of the materials with $\mathrm{CO}_{2}$. The highest values were found for $M$ and $E$, while those for $O$ and $\mathrm{B}$ showed higher values than BP, which has the largest organic bridge.

In view of the differences in $E_{\text {app }}$, the $\mathrm{CO}_{2} /$ $\mathrm{H}_{2}$ and $\mathrm{CO}_{2} / \mathrm{CH}_{4}$ permeance ratios may be further increased by applying lower temperatures. While the highest permeances were observed for the B and BP membranes, the highest fluxes at comparable selectivity are expected for the $\mathrm{O}$ membrane, as no decreasing $\mathrm{CO}_{2}$ permeance was observed at increasing pressures. While several organic polymers are known to have high selectivity towards $\mathrm{CO}_{2}$, application is hindered by insufficient stability related to swelling and increased plasticity. ${ }^{[4]}$ As hybrid silica has an inorganic $\mathrm{Si}-\mathrm{O}-\mathrm{Si}$ backbone that provides structural stability, these effects are absent in the materials, as was shown above. Hybrid organosilica membranes with larger organic bridges may therefore be further developed for applications in which high $\mathrm{CO}_{2}$ selectivity is required, such as $\mathrm{CO}_{2}$ gas capture.

Interestingly, while the end-to-end length of the organic chains of $\mathrm{BP}$ and $\mathrm{O}$ is similar, the $\mathrm{O}$ material exhibits the highest overall $E_{\text {app }}$ of all studied hybrid materials. The effect of the chain shape and conformation is substantial. The strongly temperature-dependent transport through the $\mathrm{O}$ material suggests high chain mobility, while the chains of the BP material have a much more rigid character. The flexibility of the organic bridging group therefore has a major effect on the separation performance of hybrid membranes.

The fact that the gas permeance ratios depend on the size, flexibility, and shape of the organic bridging groups is highly relevant. It indicates that the selectivity of hybrid membranes towards certain targeted molecules can be fine-tuned by variation of the nanostructure and the affinity. We followed a

Table 5. Gas permeance ratios through organosilica membranes: $\mathrm{H}_{2} / \mathrm{N}_{2}, \mathrm{CO}_{2} / \mathrm{H}_{2}$, and $\mathrm{CO}_{2} / \mathrm{CH}_{4}$ at a feed pressure of 3 bar.

\begin{tabular}{|c|c|c|c|}
\hline Membrane & $\mathrm{H}_{2} / \mathrm{N}_{2}$ permeance ratio $523 \mathrm{~K}$ & $\mathrm{CO}_{2} / \mathrm{H}_{2}$ permeance ratio $523 \mathrm{~K}$ & $\mathrm{CO}_{2} / \mathrm{H}_{2}$ permeance ratio $323 \mathrm{~K}$ \\
\hline M & 12.0 & 1.1 & 7.3 \\
\hline$E$ & 16.2 & 0.9 & 9.6 \\
\hline 0 & 5.3 & 1.6 & 4.6 \\
\hline B & 8.4 & 1.5 & 4.4 \\
\hline BP & 6.3 & 1.7 & 3.2 \\
\hline
\end{tabular}


Table 6. Water and $n$-butanol fluxes, water content of the permeate, and $\mathrm{H}_{2} \mathrm{O}$ separation factor $\alpha$ after 3 days of continuous membrane operation in 95/5 wt.\% n-butanol/water pervaporation (368 K).

\begin{tabular}{|c|c|c|c|c|}
\hline Membrane & Water flux $\left[\mathrm{kg} \mathrm{m}^{-2} \mathrm{~h}^{-1}\right]$ & $n$-butanol flux $\left[\mathrm{kg} \mathrm{m}^{-2} \mathrm{~h}^{-1}\right]$ & $\mathrm{H}_{2} \mathrm{O}$ in permeate [wt.\%] & $\alpha$ \\
\hline M & 5.5 & 0.28 & 95.1 & 388 \\
\hline$E$ & 3.4 & 0.29 & 93.4 & 283 \\
\hline $\mathrm{O}$ & 3.0 & 6.2 & 32.6 & 9.7 \\
\hline B & 3.2 & 0.25 & 92.7 & 242 \\
\hline BP & 4.5 & 2.9 & 61.2 & 31 \\
\hline
\end{tabular}

procedure with the same preparation conditions and colloid size distributions, so that we can directly relate the nanostructure and transport properties to the nature of the organic bridging group. As a great variety of possible hybrid structures exists, there is a large potential for further development of hybrid membranes. The gas separation performance can be optimized for specific molecular separations, including the technologically most relevant separations of hydrogen and carbon dioxide. The separation performance can be further improved through the selection of appropriate process conditions such as temperature. The great variety in transport activation energies renders ample opportunities to this end.

\subsection{Membrane Pervaporation Performance}

In earlier work we have already demonstrated that, due to their high hydrothermal stability, hybrid silica membranes are suitable for pervaporation applications such as the dehydration of organic solvents. ${ }^{[37-39]}$ We compared the flux and separation selectivity of this series of hybrid membranes for the separation of 5 wt. $\%$ water from $n$-butanol. Results obtained at $368 \mathrm{~K}$ after 3 days of continuous operation are shown in Table 6 . This delay time allows for a more precise comparison, as initial fluxes are usually somewhat higher and selectivities lower.

The highest separation factors were observed for the $M$, E, and B membranes, while they were much lower for the $\mathrm{BP}$ and (especially) O membranes. The water fluxes were of the same order for all membranes, while those for $n$-butanol fluxes differed greatly. This shows again that transport though hybrid membranes differs from what is generally common in ceramic membranes. The type of organic group affects the separation performance, which is likely related to hydrophobichydrophilic interactions. The best overall performance for the separation of water was obtained for the M membrane. While this membrane did not exhibit clearly different gas permeance ratios than the E membrane (Table 5), its higher dehydration selectivity and water flux may be related to a low organic fraction, and to the small pore size. The substantial difference in dehydration performance of the $\mathrm{O}$ and $\mathrm{B}$ membranes is even more remarkable, considering that the gas permeance ratios were of the same order. This can be explained by the hydrophobic character of the $\mathrm{O}$ material, as already mentioned in Section 2.2, which results in an improved interaction with $n$-butanol. Incorporation of a sizable alkylene bridge may thus lead to a hydrophobic material that can favor the separation of nonpolar molecules. No hydrophobic properties could be associated with BP. Its comparatively large pore size is likely the dominant factor for the high $n$-butanol flux. We showed before that a smaller organic bridging group resulted in an increased selectivity towards separating water from small alcohols. ${ }^{[40]}$ Similarly, materials with larger rigid bridging groups, such as BP, are potentially applicable in the pervaporation of mixtures of larger molecules.

\section{Conclusion}

We synthesized a series of microporous hybrid silica materials with alkylene and aromatic bridging groups of different sizes. Bridged silsequioxane precursor concentrations were optimized to obtain sols with $\approx 6 \mathrm{~nm}$ colloids with an open internal structure. These showed excellent processability towards microporous defect-free thin-film membranes. All hybrid materials retained their organic groups after thermal consolidation. Their molecular separation properties in gas permeation and pervaporation was affected both by the length of the organic bridges and the affinity to adsorption. The materials with the shortest $\left(\mathrm{CH}_{2}\right.$ and $\mathrm{C}_{2} \mathrm{H}_{4}$ alkylene) bridges exhibited the highest $\mathrm{H}_{2} / \mathrm{N}_{2}$ permeance ratios, indicating that these materials may be suitable for size-based molecular sieving. These materials also showed the best performance in separating $\mathrm{H}_{2} \mathrm{O}$ from $n$-butanol in a pervaporation process. The highest $\mathrm{CO}_{2} / \mathrm{H}_{2}$ permeance ratios were obtained for octane- and benzene-bridged organosilica. Considering that $\mathrm{CO}_{2}$ has a larger diameter than $\mathrm{H}_{2}$, transport through these materials is dominated by the strong affinity to $\mathrm{CO}_{2}$. Inorganic silica membranes show much lower selectivity of $\mathrm{CO}_{2}$ over $\mathrm{H}_{2}$. Both size- and affinity-based transport participate in $\mathrm{CO}_{2} / \mathrm{CH}_{4}$ permeance ratios. The octane-bridged material showed strongly temperature-dependent transport for all investigated gases. The flexibility of the organic bridge results in a material with a polymeric character, while the network backbone structure of an inorganic (silica) material is retained. The hydrophobic character of this material resulted in a high $n$-butanol flux in pervaporation. The biphenyl-bridged material also showed an enhanced $n$-butanol flux. This is probably caused by the large size and rigidity of the organic bridging group. The biphenyl-bridged material is therefore likely suitable for the separation of mixtures of larger molecules by pervaporation. While the applicability of organic polymers is often limited by plasticization, no indication for plasticization was found in hybrid silica materials. The high connectivity of the inorganic network of the hybrid silica materials makes them structurally resistant to these effects. Considering that both the nanopore 
structure and the affinity of the material can be adapted by variation of the organic bridging group, we envisage excellent prospects for optimization of hybrid membranes in a wide range of industrial molecular separations.

\section{Experimental Section}

Material Preparation: Silsesquioxane precursors (Scheme 1) were obtained from commercial suppliers: bis(triethoxysilyl)methane ('M', $A B C R$ ), 1,2-bis(triethoxysilyl)ethane ('E', ABCR), 1,8-bis(triethoxysilyl) octane ('O', ABCR), 1,4-bis(triethoxysilyl)benzene ('B', Aldrich) and 4,4'-bis(triethoxysilyl)biphenyl ('BP', Aldrich). Distilled water and nitric acid (65 wt.\%, Aldrich) were added to dry ethanol, and the silsesquioxane precursor was subsequently added to this mixture under vigorous stirring. Immediately, this mixture was placed in a closed glass container in a water bath at $333 \mathrm{~K}$, and kept at this temperature for $3 \mathrm{~h}$ under continuous stirring. All sols were synthesized with a hydrolysis ratio (number of water molecules per reactive alkoxy group) of 1 and an acid concentration of $0.18 \mathrm{~mol} \mathrm{~L}^{-1}$ (corresponding to a $\mathrm{pH}$ of 0.74 ). To result in a mean colloid size of $\approx 6 \mathrm{~nm}$, the synthesis time for some sols was decreased.

Unsupported films were obtained by drying small amounts of the sols in a Petri dish. Supported mesoporous $\gamma-\mathrm{Al}_{2} \mathrm{O}_{3}$ membranes ${ }^{[51,52]}$ were coated once with freshly prepared hybrid sols, diluted 1:1 (vol) with ethanol. Coating procedures were carried out under class 1000 cleanroom conditions. All layers were applied on the outside of the support tubes. The supported and unsupported films were consolidated by a thermal treatment at $523 \mathrm{~K}$ for $2 \mathrm{~h}$ in a nitrogen flow $(99.999 \%$ pure), applying heating and cooling rates of $0.5 \mathrm{~K} \mathrm{~min}^{-1}$.

Characterization of Hybrid Colloids, Unsupported Films, and Supported Films: Colloid sizes in the freshly prepared sols were determined by DLS. The sols were diluted with three volume parts of EtOH and the colloid size distribution was measured at $298 \mathrm{~K}$ using a Malvern Zetasizer Nano ZS.

SAXS measurements were carried out at the DUBBLE beamline BM-26B ${ }^{[56]}$ of the European Synchrotron Radiation Facility in Grenoble, France. Scattering data were obtained with $12 \mathrm{keV} \mathrm{X-rays.} \mathrm{A} \mathrm{measure} \mathrm{for}$ the degree of branching expressed by $\beta$, in other systems sometimes referred to as 'fractal dimension', was determined within $\approx 5 \%$ accuracy after background subtraction from an exponential fit of the intensity $1 \sim \mathrm{e}^{-\beta}$.

FTIR Spectroscopy was performed on dried unsupported films, stored for identical periods and under identical conditions (room temperature and ambient air) using a Diffuse Reflectance IR Fourier Transform cell in a Bio-Rad FT175 at room temperature.

Adsorption/desorption isotherms were obtained for dried $(p<$ $10^{-4}$ mbar at $473 \mathrm{~K}$ ) thermally consolidated unsupported films on a CE-Instruments 1990. $\mathrm{N}_{2}$ isotherms (kinetic diameter $0.364 \mathrm{~nm}$ ) were obtained at $77 \mathrm{~K}$, and $\mathrm{CO}_{2}, \mathrm{C}_{2} \mathrm{H}_{4}$, and $\mathrm{C}_{2} \mathrm{H}_{2}$ isotherms (kinetic diameters $0.33,0.39$, and $0.33 \mathrm{~nm}$, respectively) at $273 \mathrm{~K}$. From the adsorption isotherms, surface areas were determined by the Dubinin method, modified by Kaganer, ${ }^{[50,57,58]}$ represented by

$\log n=\log n_{m}-D\left(\log p^{0} / p\right)^{2}$

with $n$ the gas adsorbed at relative pressure $p / p^{0}, n_{m}$ the monolayer capacity of the surface, both expressed in mol per $g$ adsorbent, and $D$ a constant dependent on the interaction between adsorbent and adsorbate. Surface areas $A$ were subsequently determined according to

$A=n_{m} a_{m} N_{A}$

in which $N_{\mathrm{A}}$ is Avogadro's number and $a_{\mathrm{m}}$ the area occupied by a molecule in the completed monolayer, taken as $0.162 \mathrm{~nm}^{2}$ for $\mathrm{N}_{2}$ (ISO 9277), $0.179 \mathrm{~nm}^{2}$ for $\mathrm{CO}_{2}, 0.2195 \mathrm{~nm}^{2}$ for $\mathrm{C}_{2} \mathrm{H}_{4}$, and $0.204 \mathrm{~nm}^{2}$ for $\mathrm{C}_{2} \mathrm{H}_{2}$. The solid skeletal (network) density was determined by gas pycnometry at room temperature, with $\mathrm{He}$ as a replacement gas, in a Micromeritics Multivolume Pycnometer 1305 after the same drying procedure.

High-resolution SEM was carried out on a Jeol 6330F SEM equipped with a Noran Voyager EDX at a voltage of $5.0 \mathrm{kV}$.

Permporometry of supported hybrid membranes was carried out with water as the condensable vapor and $\mathrm{He}$ as the diffusional gas, ${ }^{[3,54]}$ applying a drying temperature of $473 \mathrm{~K}$ and a measurement temperature of $313 \mathrm{~K}$. By the application of a pressure gradient, helium transport occurred by a combination of molecular diffusion and pressure-driven transport. Pore size distributions were assessed from the adsorption isotherm by applying the Kelvin equation to the water vapor pressure:

$\ln p / p^{0}=-4 \gamma \vee \mathrm{m} / d_{p} R T$

with $p / p^{0}$ the relative water vapor pressure, $\gamma$ the surface tension, $V_{m}$ the molar volume, $d_{\mathrm{p}}$ the pore diameter, $R$ the gas constant and $T$ the temperature.

Membrane Performance: Single gas permeation rates of $\mathrm{He}, \mathrm{H}_{2}, \mathrm{~N}_{2}$, $\mathrm{CO}_{2}$, and $\mathrm{CH}_{4}$ were determined at feed pressures of 3-9 bar, a pressure difference over the membrane of 2 bar, and temperatures of 323, 423, and $523 \mathrm{~K}$. Gas modules developed in-house were used in which the temperature inside the membrane tube is measured. The preheated gas is fed at the exterior of the membrane tube. To determine the permeance, permeate and retentate gas flows were measured at fixed pressures and calculated back to permeance using the effective membrane surface.

Pervaporation of water from $n$-butanol was carried out using the supported membranes in a stirred vessel at $368 \mathrm{~K}(95 / 5 \mathrm{wt} . \% \mathrm{n}$-butanol/ water, 1 bar). Water was continuously added with a pump to compensate for the losses caused by the pervaporation process. The performance of the membranes was determined with a feed mixture containing $5 \mathrm{wt} . \%$ demineralized water in $n$-butanol (Merck PA). The permeate sides of all membranes was kept at 10 mbar with a vacuum pump. The compositions of the feed and the permeate were determined by Karl Fischer titrations. The separation factor, $\alpha$, is defined as

$\alpha=\frac{Y_{\mathrm{w}} / Y_{\mathrm{b}}}{X_{\mathrm{w}} / X_{\mathrm{b}}}$

where $Y$ and $X$ are the weight fractions of water (w) and $n$-butanol (b) in the permeate and feed solutions, respectively.

\section{Supporting Information}

Supporting Information is available from the Wiley Online Library or from the author.

\section{Acknowledgements}

This research was financially supported by the EOS technology programme of the Dutch Ministry of Economic Affairs administered by AgentschapNL. We are grateful to the Netherlands Organisation for the Advancement of Research (NWO) for providing us with the possibility of performing SAXS measurements at the Dutch-Belgian Beamline (DUBBLE) at ESRF, and to Dr. Giuseppe Portale, Dr. Kristina Kvashnina and Dr. Wim Bras at DUBBLE for their on-site assistance. We thank Mariëlle Rietkerk and Donough Shanahan of the Energy research Centre of the Netherlands and Dr. Andrei Petukhov from the University of Utrecht for their assistance in experimental work.

Received: November 9, 2010

Revised: January 13, 2011

Published online: April 12, 2011 
[1] Pervaporation Membrane Separation Processes, 1st ed. (Ed: R. Y. M. Huang), Elsevier Science, Amsterdam, The Netherlands, 1991.

[2] P. D. Chapman, T. Oliveira, A. G. Livingston, K. Li, J. Membr. Sci. 2008, 318, 5 .

[3] Recent Advances in Gas Separation by Microporous Ceramic Membranes (Ed: N. K. Kanellopoulos), Elsevier Science, Amsterdam, The Netherlands, 2000.

[4] P. Bernardo, E. Drioli, G. Golemme, Ind. Eng. Chem. Res. 2009, 48, 4638.

[5] M. B. Hägg, R. Quinn, MRS Bulletin 2006, 31, 750.

[6] H. Q. Lin, E. Van Wagner, B. D. Freeman, L. G. Toy, R. P. Gupta, Science 2006, 311, 639.

[7] Y. S. Li, H. Zhou, G. Q. Zhu, J. Liu, W. S. Yang, J. Membr. Sci. 2007, 297, 10.

[8] M. Noack, P. Kolsch, R. Schafer, P. Toussaint, J. Caro, Chem. Eng. Technol. 2002, 25, 221.

[9] J. Caro, M. Noack, P. Kolsch, Adsorption 2005, 11, 215.

[10] H. Verweij, Y. S. Lin, J. H. Dong, MRS Bulletin 2006, 31, 756.

[11] L. M. Vane, J. Chem. Technol. Biotechnol. 2005, 80, 603.

[12] J. Sekuli, J. E. ten Elshof, D. H. A. Blank, Adv. Mater. 2004, 16, 1546.

[13] T. Van Gestel, H. Kruidhof, D. H. A. Blank, H. J. M. Bouwmeester, J. Membr. Sci. 2006, 284, 128.

[14] J. Sekuli, A. Magraso, J. E. ten Elshof, D. H. A. Blank, Micropor. Mesopor. Mater. 2004, 72, 49

[15] R. M. de Vos, H. Verweij, Science 1998, 279, 1710

[16] R. M. de Vos, H. Verweij, J. Membr. Sci. 1998, 143, 37.

[17] B. N. Nair, J. W. Elferink, K. Keizer, H. Verweij, J. Sol-Gel Sci. Technol. $1997,8,471$.

[18] B. N. Nair, K. Keizer, T. Okubo, S. I. Nakao, Adv. Mater. 1998, 10, 249.

[19] J. Sekuli, J. E. ten Elshof, D. H. A. Blank, J. Membr. Sci. 2005, 254, 267.

[20] A. Larbot, A. Julbe, C. Guizard, L. Cot, J. Membr. Sci. 1989, 44, 289.

[21] R. J. R. Uhlhorn, M. Veld, K. Keizer, A. J. Burggraaf, J. Mater. Sci. Lett. 1989, 8, 1135.

[22] R. S. A. Delange, J. H. A. Hekkink, K. Keizer, A. J. Burggraaf, J. Membr. Sci. 1995, 99, 57.

[23] R. J. R. Uhlhorn, M. Intveld, K. Keizer, A. J. Burggraaf, J. Mater. Sci. 1992, 27, 527

[24] V. Boffa, J. E. ten Elshof, A. V. Petukhov, D. H. A. Blank, ChemSusChem 2008, 1, 437.

[25] V. Boffa, J. E. ten Elshof, R. Garcia, D. H. A. Blank, Micropor. Mesopor. Mater. 2009, 118, 202.

[26] V. Boffa, J. E. ten Elshof, D. H. A. Blank, J. Membrane Sci. 2008, 319, 256.

[27] H. Imai, H. Morimoto, A. Tominaga, H. Hirashima, J. Sol-Gel Sci. Technol. 1997, 10, 45.

[28] R. Kreiter, M. D. A. Rietkerk, B. C. Bonekamp, H. M. van Veen, V. G. Kessler, J. F. Vente, J. Sol-Gel Sci. Technol. 2008, 48, 203.

[29] J. Campaniello, C. W. R. Engelen, W. G. Haije, P. Pex, J. F. Vente, Chem. Commun. 2004, 834.

[30] J. C. D. da Costa, G. Q. Lu, V. Rudolph, Colloids Surf., A 2001, 179, 243.
[31] R. M. de Vos, W. F. Maier, H. Verweij, J. Membr. Sci. 1999, 158, 277.

[32] H. L. Castricum, A. Sah, M. C. Mittelmeijer-Hazeleger, C. Huiskes J. E. ten Elshof, J. Mater. Chem. 2007, 17, 1509.

[33] R. Igi, T. Yoshioka, Y. H. Ikuhara, Y. Iwamoto, T. Tsuru, J. Am. Ceram. Soc. 2008, 91, 2975.

[34] M. C. Duke, J. C. Diniz da Costa, D. D. Do, P. G. Gray, G. Q. Lu, Adv. Funct. Mater. 2006, 16, 1215.

[35] D. A. Loy, K. J. Shea, Chem. Rev. 1995, 95, 1431

[36] K. J. Shea, D. A. Loy, Chem. Mater. 2001, 13, 3306.

[37] H. L. Castricum, A. Sah, R. Kreiter, D. H. A. Blank, J. F. Vente, J. E. ten Elshof, Chem. Commun. 2008, 1103.

[38] H. L. Castricum, A. Sah, R. Kreiter, D. H. A. Blank, J. F. Vente, J. E. ten Elshof, J. Mater. Chem. 2008, 18, 2150.

[39] H. L. Castricum, R. Kreiter, H. M. van Veen, D. H. A. Blank, J. F. Vente, J. E. ten Elshof, J. Membr. Sci. 2008, 324, 111.

[40] R. Kreiter, M. D. A. Rietkerk, H. L. Castricum, H. M. van Veen, J. E. ten Elshof, J. F. Vente, ChemSusChem 2009, 2, 158.

[41] G. Dubois, W. Volksen, T. Magbitang, R. D. Miller, D. M. Gage, R. H. Dauskardt, Adv. Mater. 2007, 19, 3989.

[42] W. Volksen, R. D. Miller, G. Dubois, Chem. Rev. 2010, 110, 56

[43] R. Kreiter, M. D. A. Rietkerk, H. L. Castricum, H. M. van Veen, J. E. ten Elshof, J. F. Vente, J. Sol-Gel Sci. Technol. 2011, DOI 10.1007/s10971-010-2208-7.

[44] M. Kanezashi, K. Yada, T. Yoshioka, T. Tsuru, J. Membr. Sci. 2010, $348,310$.

[45] M. Kanezashi, K. Yada, T. Yoshioka, T. Tsuru, J. Am. Chem. Soc. 2009, $131,414$.

[46] C. J. Brinker, G. C. Frye, A. J. Hurd, C. S. Ashley, Thin Solid Films 1991, 201, 97

[47] H. L. Castricum, A. Sah, J. A. J. Geenevasen, R. Kreiter, D. H. A. Blank, J. F. Vente, J. E. ten Elshof, J. Sol-Gel Sci. Technol. 2008, 48, 11.

[48] R. S. A. Delange, J. H. A. Hekkink, K. Keizer, A. J. Burggraaf, J. NonCryst. Solids 1995, 191, 1

[49] A. Guinier, Ann. Phys. 1939, 12, 161.

[50] M. M. Dubinin, L. V. Radushkevich, Proc. Acad. Sci. USSR 1947, 55, 331.

[51] B. C. Bonekamp, in Fundamentals of Inorganic Membrane Science and Technology (Eds: A. J. Burggraaf, L. Cot), Elsevier, Amsterdam, The Netherlands, 1996.

[52] H. M. van Veen, Y. C. van Delft, C. W. R. Engelen, P. Pex, Sep. Purif. Technol. 2001, 22-23, 361.

[53] T. Tsuru, T. Hino, T. Yoshioka, M. Asaeda, J. Membr. Sci. 2001, 186, 257.

[54] H. W. Deckman, R. R. Chance, D. M. Cox, W. G. deGijnst, J. J. Reinoso, US Patent 2003/0005750, 2003.

[55] R. S. A. de Lange, Microporous Sol-Gel Derived Ceramic Membranes for Gas Separation-Synthesis, Gas Transport and Separation Properties, PhD thesis, University Twente, The Netherlands, 1993.

[56] W. Bras, Nucl. Instrum. Methods Phys. Res., Sect. B 2003, 199, 90.

[57] M. G. Kaganer, Zh. Fiz. Khim. 1959, 33, 2202.

[58] S. J. Gregg, K. S. W. Sing, Adsorption, Surface Area and Porosity, Academic Press, London, UK, 1982. 